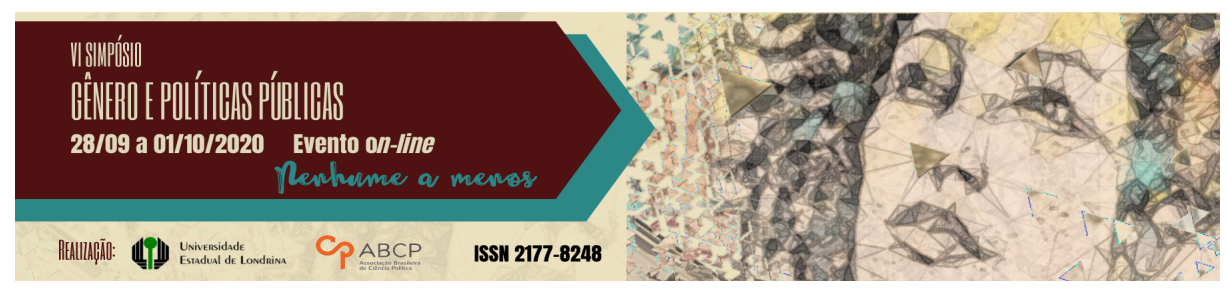

\title{
O caso Eloá Pimentel (2008): narrativas sobre violência de gênero
}

\author{
Laís Pinheiro de Souza Guelis ${ }^{1}$
}

\section{Resumo}

No final do ano de 2008, a adolescente Eloá Cristina Pimentel foi mantida refém pelo ex-namorado em seu apartamento juntamente com a amiga Nayara Rodrigues. Após cerca de cem horas, o cativeiro acabou com a entrada da polícia e o saldo foi a morte de Eloá com tiros na cabeça e virilha, ferimento da amiga Nayara com um tiro no rosto e a prisão do rapaz. O presente trabalho se ocupa em explorar as narrativas construídas sobre o caso em alguns veículos da imprensa e suas representações no curso da última década, bem como compreender quais os possíveis caminhos que levaram o caso a ganhar dimensão nacional. Em seguida, utilizando concepções de Gênero enquanto uma categoria de análise decolonial, ressalto as especificidades dessas violências na América Latina, discutindo de que forma as posições de gênero colocaram os corpos femininos ou feminizados em situação de vulnerabilidade.

Palavras-chave: narrativas, violência de gênero, feminicídio.

\section{The Eloá Pimentel case (2008): narratives about gender violence}

\begin{abstract}
In 2008 Eloá Cristina Pimentel and Nayara Rodrigues were held hostage by Eloá's ex-boyfriend in the apartment where she lived with her family. After about a hundred hours, the police invaded the location resulting in the death of Eloá with shots to the head and groin and the wound of his friend Nayara

1 Licenciada em História pela Universidade Estadual de Maringá e Mestranda no Programa de Pós Graduação em Ciências Sociais pela mesma Universidade. E-mail para contato: lpinheiroguelis@gmail.com.
\end{abstract}

GT 17 - Policiamento Plural e Dinâmicas de Gênero 
with a shot to the face. The present work aims to explore the narratives constructed about the case in the Brazilian press and their representations over the course of the last decade, as well as to understand the possible paths that led the case to gain national dimension. Starting from a Decolonial perspective, I prioritize the configurations of feminicide in Latin America, discussing how gender positions have placed female or feminized bodies in a situation of vulnerability in the most diverse types of violence.

Keywords: narratives, gender violence, feminicide.

Entre os dias 13 e 17 de outubro de 2008, milhares de brasileiros acompanharam os acontecimentos de um pequeno apartamento do Conjunto Habitacional Companhia de Desenvolvimento Habitacional Urbano (CDHU), periferia de Santo André. Esse lugar, por mais ordinário que parecesse, foi palco do que mais tarde receberia da imprensa o questionável título de "o mais longo caso de cárcere privado da história do Estado de São Paulo"2.

Na segunda-feira (13), Eloá Cristina Pimentel na época com quatorze anos, recebeu alguns amigos no prédio onde morava com o pai Everaldo Pereira dos Santos, a mãe Ana Cristina Pimentel, o irmão mais velho Ronickson Pimentel, e o caçula Douglas Pimentel. Nayara Rodrigues, Iago Vilera e Victor Campos cursavam junto com a adolescente o primeiro ano do Ensino Médio na Escola Estadual José Carlos Antunes e na ocasião se reuniram para fazer um trabalho de Geografia que deveria ser finalizado pouco antes do fim do ano letivo.

Nayara e Eloá nutriam uma convivência bastante constante e conforme descreveu uma matéria ${ }^{3}$ da Folha de São Paulo no dia 18 de outubro de 2008, na rede social Orkut as duas se apresentavam como

\footnotetext{
2 Cronologia do caso disponível em: https://www1.folha.uol.com.br/cotidiano/2008/10/457514-veja-cronologia-de-casode-jovem-que-manteve-ex-namorada-refem-em-santo-andre-sp.shtml. Acesso em: 3 jun. 2019.

3 Eloá ficou mais próxima de nayara ao terminar o namoro. Disponível em: https://www1.folha.uol.com.br/fsp/cotidian/ff1810200808.htm. Acesso em: 11 ago. 2020.
} 
melhores amigas e apareciam em diversas fotos juntas, inclusive em álbuns exclusivos. Embora na época, Iago e Nayara estavam namorando, não se pode afirmar que Victor e Eloá também tivessem algum tipo de envolvimento.

Por volta da uma da tarde, o apartamento onde a reunião acontecia foi invadido. $\mathrm{O}$ auxiliar de produção e motoboy Lindemberg Fernandes Alves de 21 anos, ex-namorado de Eloá, entrou armado na residência onde os adolescentes estavam, ameaçou matá-la e em seguida cometer suicídio.

Ainda no dia 13 o pai de um dos colegas presentes no apartamento, preocupado com o sumiço do filho, acionou o Grupamento de Ações Táticas Especiais, o GATE, que chegou ao CDHU por volta das 20:00. Logo nas primeiras horas de negociação com a polícia, Lindemberg liberou Iago e Victor, mantendo apenas Eloá e Nayara como suas reféns.

A negociação entre polícia e sequestrador oscilava entre momentos de tensão latente e de aparente calmaria. Dentre as estratégias usadas pelo GATE estavam longas conversas com o interior da casa, a presença das irmãs mais velhas, o corte de energia elétrica do local. Na noite do dia 14, Nayara é liberada e recrutada para auxiliar no diálogo com Lindemberg, que se mostrava cada vez mais agressivo com Eloá.

Entretanto, apesar do comportamento hesitante, no dia 16 a polícia fecha um acordo de rendição com o rapaz e autoriza a volta de Nayara ao cativeiro, o que supostamente auxiliaria no desfecho do caso. O acordo foi quebrado e a garota volta a ser subordinada junto com a melhor amiga.

No dia seguinte, por volta das 18:00 o comandante do Batalhão de Choque da PM Eduardo Félix decide arrombar o apartamento, posteriormente alegando ter ouvido um disparo que vinha de dentro. Durante a invasão Lindemberg atirou em Eloá na região da virilha e da cabeça e em Nayara no rosto, antes de ser dominado e preso. Após dar entrada no Hospital Municipal de Santo André em estado gravíssimo, Eloá foi declarada morta no dia 18 de outubro e seus órgãos foram 
doados. Nayara passou por várias cirurgias, mas sobreviveu aos tratamentos.

Na década que se seguiu após o crime, essa narrativa foi construída a partir de diversas perspectivas e atendendo às inúmeras necessidades e formatos. Coberturas ao vivo, reportagens, especiais de investigação jornalísticas, por livros da área de direito e investigações criminais, por teses de doutorado, por documentários e mais uma vez é aqui recontada.

Quando me debrucei na escrita do projeto que se desdobra nesta atual pesquisa, tinha algumas pistas do caminho que gostaria de percorrer. Em 2018, em uma conversa com um amigo sobre o livro Crime do Restaurante Chinês (2009), de Bóris Fausto, começamos a relembrar justamente dos crimes que, assim como o do assunto central da obra de Fausto, haviam causado alguma repercussão para a nossa geração. Foi quando me lembrei de Eloá e dos questionamentos aos quais tive acesso em um espaço virtual de discussões feministas que me apresentou o documentário Quem matou Eloá? logo em seu ano de lançamento, em $2015^{4}$.

No meio de tantos outros pensamentos, se sobressaiu a lembrança do meu "eu" adolescente: aquele que acompanhou assiduamente o caso pela televisão e que o fez com sentimento de vulnerabilidade.

Partindo de tais inquietações, formulei inicialmente um esboço de objeto científico, com seus limites e necessidades, mantendo em mente que o enredo trágico e o apelo sensacionalista das mídias não foram os únicos motivos que me ligaram ao crime ou que transformaram a vida e morte dessa garota em um assunto presente nas minhas conversas com familiares e amigos da época.

4 Ano de aprovação da Lei 13.104/2015 que aprova o feminicídio enquanto circunstância qualificadora no homicídio. 
Em 2008, eu estava com quatorze anos e passava também por um rompimento bastante conturbado de um namoro. Diante disso, acreditei que sentir medo e ouvir ameaças de um ex-namorado fazia parte de uma espécie de elemento incluso na jornada de se tornar uma mulher e que, de alguma forma, eu estava vivendo as consequências de minhas próprias escolhas infelizes, do mesmo modo que eu considerava que Eloá vivia.

Aos poucos, conforme eu vivenciava a adolescência e ingressava na vida adulta, fui percebendo que apesar do chamado "Caso Eloá" ter assumido grande repercussão na opinião pública, não era raro ouvir histórias e encontrar meninas e mulheres que viviam situações parecidas. Eu me identifiquei com Eloá assim como muitas de minhas colegas se identificaram naquele momento ou muitos anos depois. Seria possível que todas nós tivéssemos feito escolhas tão equivocadas como mera coincidência de infelicidades na vida?

Quando converso com mulheres à minha volta ou me ocupo em fazer uma rápida busca em qualquer site de notícias a ideia de que se trata apenas de uma porção de homens desequilibrados, doentes e fora do padrão de "normalidade" vai se afastando para dar lugar a percepção de que, na verdade, esses casos são sintomas.

Ressalto que o modo de narrar aqui exposto parte de uma trajetória completamente circunscrita ao meu lugar social de mulher branca e acadêmica, inserida nesses espaços de debate. A partir disso, não tenho as condições de afirmar que este caso segue presente na memória constante de mulheres brasileiras. No entanto, é possível assegurar que os elementos simbólicos que perpassam a história não são, de forma alguma, estranhos às experiências femininas, especialmente no Brasil e em toda a América Latina. 


\section{Objetivos}

Se reconhecer como pesquisadora, imbuída de subjetividades, enquanto lança um olhar analítico para o seu objeto de investigação é um dos grandes desafios do exercício da escrita dentro das Ciências Humanas. Ao passo que compreendo e pontuo esses processos, ainda que de forma tímida e superficial, acrescento camadas importantes na elaboração da pesquisa, no entendimento do objeto e no trabalho com a documentação.

Na trajetória de elaboração desta pesquisa, as chaves de leitura na perspectiva decolonial se mostraram extremamente relevantes para os caminhos pretendidos para a análise do objeto. Somos formadas diante da perspectiva de ciência eurocentrada, que desde a base do seu processo de construção se pretendeu enquanto única e se ocupa em elaborar narrativas que sejam homogeneizantes e a serviço de uma lógica colonizadora.

Dito isso, afirmo que não existe a pretensão de apresentar um modelo científico inovador que dê conta de todas as especificidades ou mesmo que rompa de forma integral com referências americoeurocentradas, mas sim pontuar alguns caminhos para um exame crítico direcionado a concepções dadas como postas.

Dessa forma, este texto tem como objetivo apresentar brevemente algumas narrativas construídas sobre o caso em alguns veículos da imprensa, bem como compreender de que forma as discussões sobre violência de gênero e feminicídio foram sendo desenvolvidas em paralelo. Como base para as análises, evoco primeiramente o conceito de Trauma Cultural de Ron Eyerman que permite pensar de que forma o caso ganhou dimensão nacional e como a construção de uma narrativa de vida e morte de Eloá se tornou significativa num aspecto micro e macro.

Também utilizo a socióloga María Lugones que concebe Gênero enquanto uma categoria de análise decolonial, possibilitando a 
compreensão da construção hierárquica do ser mulher nas especificidades da América Latina. Por fim, partindo da mesma chave de leitura, a antropóloga Rita Segato ao falar sobre feminicídio das mulheres latinas, discute de que forma a conformação das posições de gênero colocaram os corpos femininos ou feminizados em situação de vulnerabilidade as mais diversas violências.

\section{Narrativas e Representações}

Lindemberg e Eloá se conheceram justamente no conjunto CDHU, onde ele também morava junto com a mãe e, entre idas e vindas, namoraram por dois anos e sete meses. A família da menina não gostava da ideia no início do relacionamento, principalmente pela pouca idade da filha. Uma reportagem do jornal Folha de São Paulo do dia 18 de outubro descreveu o namoro como um "romance préadolescente", apesar do rapaz já ter 19 anos e Eloá apenas 12.

Com o passar do tempo, a relação passou a ser mais bem aceita pelos pais dela. Na ocasião do julgamento de Lindemberg em 2012, em meio a críticas por permitir uma menina tão jovem a namorar, Ana Cristina deu uma declaração ${ }^{5}$ dizendo que autorizou o namoro justamente para evitar que eles se relacionassem escondido.

O último término dos dois partiu do rapaz e Eloá acatou a decisão concordando ser o melhor para os dois o que deixou Lindemberg "conturbado"6 e com comportamentos persecutórios, chegando a agredir Eloá em um ponto de ônibus dias antes do crime.

\footnotetext{
5 Disponível em: https://noticias.uol.com.br/cotidiano/ultimasnoticias/2012/02/27/mae-de-eloa-diz-que-. $\quad$ autorizou-relacionamento-comlindemberg-para-evitar-namoro-escondido.html. Acesso em: 13 set. 2018.

6 Declaração de Nayara Rodrigues sobre o comportamento de Lindemberg pós término. Disponível em: http://g1.globo.com/sao-paulo/noticia/2012/02/ele-meodiava-e-odiava-minha-mae-diz-nayara-sobre-lindemberg.html. Acesso em: 13 set. 2018.
} 
Durante os dias de sequestro muito se especulou sobre a natureza da relação dos dois e principalmente sobre o passado do sequestrador. Para os amigos dele, era um "menino bom, que nunca se envolveu com o crime ou com drogas. Nem bebia". Para as irmãs, ele "não era bandido, era trabalhador" que simplesmente não soube lidar com o término e entrou em depressão. Já outros vizinhos e alguns amigos de Eloá descreveram Lindemberg como "ciumento", "possessivo" e "arrogante".

As coberturas midiáticas, que transitavam entre as mais sóbrias e as mais sensacionalistas, tinham como ponto em comum a busca frenética pelo grande furo de reportagem. Um dos exemplos que mais se destacaram nesse cenário foi o "A Tarde é Sua" da RedeTv.

Comandado pela apresentadora Sônia Abrão, o programa televisionou uma entrevista ao vivo com o sequestrador pelo telefone. Abrão, que contava com um corpo de analistas ao vivo, ocupou um espaço de "apaziguadora" segundo a própria, onde buscava demonstrar ao outro lado da linha uma preocupação quase materna:

O pessoal que te conhece também está falando que você sempre foi calmo, sempre foi trabalhador, sempre foi um cara legal, que o que você tá fazendo hoje deve ser um surto que você tá passando, é uma crise emocional muito séria $[\mathrm{sic}]^{7}$.

O crime envolvia um motivo "passional", violência marcante e três protagonistas jovens, periféricos e até segunda ordem, inocentes. Apesar de conter um enredo suficientemente capaz de

mobilizar as famílias do país, não se tratava de algo exatamente inusitado. Vale ressaltar que de acordo com o "Mapa da Violência 2012", após uma leve queda nos índices de violência contra mulheres, foi justamente no ano de 2008 que os números voltaram a crescer novamente.

7 Entrevista disponível em: https://www.youtube.com/watch?v=9_gSLc0oCic. Acessado em 15 set. 2018. 
As notícias sobre o assunto tiveram dois principais momentos de veiculação expressiva. O primeiro se deu nos últimos meses de 2008 e o segundo foi na ocasião do julgamento de Lindemberg em 2012. Em 2015, em meio a discussões sobre a lei $\mathrm{N}^{0} 13.104$, mais conhecida como Lei do Feminicídio, que pretende classificar como específicas as mortes ocasionadas por atentados que envolvem a discriminação contra a condição de mulher ou por violência doméstica e familiar, o caso volta para as pautas graças ao documentário “Quem Matou Eloá?”.

Produzido pela diretora Lívia Perez, o curta-metragem de 24 minutos percorre um caminho de criticar a chave romântica por muitas vezes atribuída pela mídia aos casos de violência contra mulheres, problematizando os elementos técnicos utilizados para construir através da edição uma atmosfera de filme de ação. Os principais eixos abordados no roteiro foram a questão de violência de gênero e sua romantização, o despreparo do aparato policial para lidar com tais situações e a urgente necessidade de enquadrar esses crimes enquanto feminicídio. $\mathrm{O}$ documentário recebeu diversos prêmios tanto nacional como internacionalmente.

\section{Possibilidades analíticas}

No artigo intitulado "Harvey Milk and the Trauma of Assassination", publicado em 2012, o sociólogo Ron Eyerman apresenta na prática de que forma os conceitos de Drama Social e Trauma Cultural se aplicam na análise dos assassinatos dos políticos estadunidenses Harvey Milk e George Moscone, ambos executados na prefeitura no 27 de novembro de 1978 por um policial conhecido da cidade de São Francisco, Califórnia. Mais especificamente, o autor se propõe a pensar sobre as narrativas, memórias e significados atrelados ao acontecimento.

Compreender determinados fatos sob a ótica analítica do Drama Social significa enxergá-los enquanto sendo performances 
ordenadas e estruturadas pelos seus agentes em um contexto de "mundo cultural compartilhado" (EYERMAN, 2012). Em outras palavras, o drama social prevê a circunscrição de um contexto temporal e espacial, centrais enquanto produtores de significados e habitado por atores que representam os papéis que de alguma forma lhes cabem - protagonistas ou coadjuvantes, construindo e agindo pelas tramas.

Nessa perspectiva, um acontecimento seria objeto passível dessa análise uma vez que a história contasse com um desfecho, uma reorganização da memória coletiva, um período de luto e uma comemoração institucionalizada. Entretanto, o que faz com que determinado acontecimento passe a ser digno de reatualização? O que causa o Trauma Cultural, que segundo o autor é esse elemento de ruptura na lógica normalizada dos acontecimentos? O que possibilitou que o Caso Eloá, em última instância, não se tornasse apenas mais uma tragédia televisionada?

Segundo Eyerman, são muitos os fatores que precisam ser considerados. Um evento se constitui enquanto digno de rememoração a partir do momento em que as chamadas estruturas políticas, sociais e simbólicas se convergem. Essa ligação, no caso do nosso objeto é fomentada justamente pelo elemento mídia, que afere significância maior a determinados eventos a partir das reconstruções narrativas.

Outro fator a ser considerado é a comunidade, ou seja, o grupo social que um dos elementos poderia se identificar em vida e depois em sua morte, através de uma espécie de "martirização" que é capaz de fomentar continuidade no processo de mobilização através de discursos dos seus intelectuais, por exemplo. Tal hipótese poderia ser transposta para o Caso Eloá no tocante a sua utilização enquanto exemplo de feminicídio dentro de um campo de disputas políticas e narrativas engajadas pelo movimento feminista brasileiro, vide o discurso em certa medida inaugurado pelo documentário “Quem Matou Eloá?". 
Entretanto, é preciso que se façam algumas ressalvas: com acesso a um grande número de casos que contém muitas vezes os mesmos requintes de crueldade ou até "maiores" - se é que isso se pode medir - o fato do sequestro ter tido um grande alcance de divulgação midiática é mesmo o suficiente por si só para um processo de martirização? Aliás, posso realmente afirmar que esse processo existiu?

Pode-se enxergar de forma nítida que nas narrativas montadas sobre Eloá recaem o jugo colonial - racista, machista e cristão - por se tratar de alguém que ora foi morta por suas más escolhas, ora pela sua atitude "promíscua" de namorar tão cedo, hora por sua ingenuidade, ainda que sua existência e localização simbólica e geográfica seja inteiramente marcada pelas próprias estruturas que a condenam mesmo depois de morta.

Se no Drama Social podemos tratar isso enquanto uma convergência de contextos marcada por um trauma maior, a chave de leitura decolonial entra no limites do conceito justamente para mostrar que esse trauma aqui não só já existia como é o fundador do sistema mundo, da modernidade ocidental.

\section{Gênero e Colonialidade}

Ora, não é incomum a discussão de Gênero figurar entre os debates considerados específicos muito embora façamos parte de uma sociedade genderizada, ou seja, pensamos e vivemos a partir dos seus parâmetros enraizados.

A filósofa María Lugones aponta no texto "Rumo a um feminismo descolonial" (2014) que a concepção de Gênero e de seus papéis dentro da modernidade $^{3}$ é caracterizada de forma hierárquica, completamente esculpida por uma moral cristã que chega às Américas através da colonização, que delimitava muito além do significado do ser homem ou mulher, mas também o de ser humano. Isso quer dizer que por não 
atender aos ideais de civilização, os povos Ameríndios e os Africanos escravizados eram considerados selvagens, "menos-humanos", homens e mulheres de segunda categoria:

Ela [a colonização] veio acompanhada por outras distinções hierárquicas dicotômicas, incluindo aquelas entre homens e mulheres. Essa distinção tornou-se a marca do humano e a marca da civilização. Só os civilizados eram homens ou mulheres (LUGONES, 2014, p. 936).

O ideal burguês da mulher dita civilizada é aquele que em que é branca, pacata, pura em seus pensamentos e nos seus corpos, que abdica de suas vontades e aceita o seu destino de forma obediente, que é o de ficar ao lado de um homem, reproduzir e cuidar com devoção de toda sua família. É compreender e ensinar as figuras masculinas em sua vida, enquanto à eles cabe todo o direito de transitar e decidir nos espaços de poder.

Eloá representou a forma não-desejável, reprovável ou até mesmo repulsiva de ser mulher: aquela que perde sua pureza de maneira descuidada, aquela que fez más escolhas, aquela que se colocou em uma relação perigosa, parte por desinformação ou inocência e parte porque de alguma forma aquele era o seu destino enquanto sendo periférica e de cor.

Com isso não quero aqui afirmar que Lindemberg é o arquétipo perfeito do homem burguês colonizador. É preciso se levar em conta o conteúdo histórico da construção dos corpos sexuados, uma vez que a formação dos sujeitos não é de estrutura binária ou linear.

Todavia, evoco aqui o trabalho de Rita Segato "Gênero e colonialidade: em busca de chaves de leitura e de um vocabulário estratégico decolonial" (2012). Diferente de Lugones, a autora aponta evidências que nos mostram que na pré-intrusão havia em grande parte dos povos algum tipo de distinção, por vezes até hierárquica entre masculino e feminino, mas que essas diferenças eram de certa forma 
contornáveis e compatíveis com a cosmovisão que as geraram - é o que ela vai chamar de patriarcado de baixa intensidade.

Entretanto, ressalta que com a chegada dos europeus e o início da colonização, houve a necessidade de se firmar acordos e alianças e estas foram essencialmente masculinas. Assim as posições de gênero vão se conformando de maneira que coloca os corpos femininos ou feminizados em situação de vulnerabilidade e extrema violência, especialmente aqueles não-brancos.

Segato se ocupa em falar sobre feminicídio na América Latina e ressalta já naquele momento que estamos vivendo o que chama de genocídio de gênero. Vidas de mulheres são ceifadas a nossa volta o tempo todo de formas emblemáticas pela sua crueldade. Se trata de "formas de destruição corporal sem precedentes, [...] formas de tráfico e comercialização de tudo o que esses corpos podem oferecer, até o seu limite" (SEGATO, 2012).

Do dia para a noite, não só o espaço doméstico da família Pimentel como o corpo de Eloá torna-se espaço de interesse do público geral. Pessoas de todo o país acompanharam os momentos finais da vida daquela adolescente e cerca de 10 mil estavam no cortejo fúnebre. Isso, na perspectiva da autora, se constitui em um sintoma, algo que confere um sentido mais profundo do que apenas o da curiosidade ou empatia pelo desfecho trágico da história:

Com a emergência da grade universal moderna, da qual emana o Estado, a política, os direitos e a ciência, tanto a esfera doméstica como a mulher que a habita transformaram-se em meros restos, na margem dos assuntos considerados de relevância universal e perspectiva neutra (SEGATO, 2012).

Para concluir, me utilizo da ideia da autora Camilla de Magalhães Gomes presente em "Gênero como categoria de análise decolonial" (2018) de que Gênero pode ser usado como categoria de luta política ou forma de produzir conhecimento. Utilizá-lo combinado a perspectiva da 
Decolonialidade significa se apossar de ferramentas que nos permitem borrar as hierarquias e binariedades.

Mais do que isso, permite pensar nossos objetos levando em consideração que o que entendemos por gênero e seus papéis foi construído no performativo da colonialidade, tendo a raça e o racismo como partes dessa formação,forjados na mesma matriz.

\section{Referências}

EYERMAN, R. Harvey Milk and the Trauma of Assassination. Cultural Sociology, p. 400-421, 2012.

GOMES, C. M. Gênero como categoria de análise decolonial. Civitas, Porto Alegre, v. 18, n. 1, p. 65-82, Apr, 2018.

LUGONES, M. Rumo a um feminismo descolonial. Rev. Estud. Fem., Florianópolis, v. 22, n. 3, p. 935-952, dez. 2014.

SEGATO, R. Gênero e colonialidade: em busca de chaves de leitura e de um vocabulário estratégico descolonial, e-cadernos ces[Online], 18, dez. 2012. 